$A B R A H A M \quad C A R M \in L I$

$G R \in T C H \in N \quad M . S P R \in I T Z \in R$

\title{
Trust, Connectivity, and Thriving: Implications for Innovative Behaviors at Work
}

\begin{abstract}
This study examines how trust, connectivity and thriving drive employees' innovative behaviors in the workplace. Using a sample of one hundred and seventy two employees across a variety of jobs and industries, we investigated the relationship between trust, connectivity (both measured at Time 1), thriving and innovative work behaviors (both measured at Time 2). Trust and connectivity were hypothesized to create a nurturing environment that enables people to thrive and be innovative in their work. The results of structural equation modeling (SEM) indicate a sequential mediation model in which connectivity mediates the relationship between trust and thriving, and thriving mediates the relationship between connectivity and innovative behaviors. The theoretical and practical implications for employee thriving and innovative behaviors at work are discussed.
\end{abstract}

Key Words: Thriving, Innovative Behaviors, Connectivity, and Trust.

\section{INTRODUCTION}

There has been growing scholarly interest in understanding human thriving at work. Much had been published in the popular realm on how to "survive and thrive" on almost any topic that involves a challenge (such as finding a job or firing a subordinate), but little research had been conducted on what it really means to thrive or why thriving matters for both employees and their organizations. Recently, conceptual work on thriving suggests that when people in work organizations are thriving, they feel progress and momentum in their work. Thriving is defined as the joint experience of a sense of learning (growing and getting better at what one does at work) and a sense of vitality (feeling energized and alive at work) (Spreitzer, Sutcliffe, Dutton, Sonenshein, \& Grant, 2005). These dimensions can be seen as reflecting the cognitive (learning) and affective (vitality) foundations of personal growth. Although theory and research on thriving are relatively nascent (Warr, 2007), thriving is generally argued to increase both 
short-term individual functioning and long-term adaptability at work (Spreitzer et al., 2005). For example, individual thriving at work has been found to be associated with organizationally relevant work outcomes. In a study that crossed levels of the organizational hierarchy and different industries, thriving has been found to be associated with better individual task performance and more organizational citizenship behaviors (including courtesy, altruism, and civic virtue) (Porath, Spreitzer $\mathcal{E}$ Gibson, 2007). Moreover, when individuals report they are thriving, they have healthier lifestyle behaviors and can adjust better to changing life conditions (such as adjustment to a MBA program) (Spreitzer, Cobb, \& Stevens, 2007).

While these studies have contributed to our understanding of the concept of thriving and its effect on work outcomes such as task performance and adjustment to changing conditions, we have yet to see studies that examine thriving at work in relation to more creative or innovative behaviors. Creativity may be defined as the production of novel and useful ideas (Amabile, 1983; Mumford $\varepsilon$ Gustafson, 1988). Innovative behavior goes beyond creativity to include the adoption, production, and implementation of novel and useful ideas (Scott $\varepsilon$ Bruce, 1994). Innovative behaviors at work include actions such as seeking out new ideas, championing ideas at work, and securing funds/planning for the implementation of ideas (Scott $\&$ Bruce, 1994). This type of behavior requires more risk and out-of-the-box thinking than the work related outcomes of thriving studied to date - it is less focused on compliance and fitting in with the status quo. The relationship between thriving and innovative behavior is the focus of our research.

While understanding the relationship between thriving at work and innovation helps expand our understanding how and why thriving matters at work, our study also contributes to the literature on creative and innovative behavior. As Ward (2004) suggested, creativity is a complex phenomenon that requires theoretical models that combine cognitions, personality traits, affect, and environmental influences. Most research, however, tends to examine one or two of these components in relative isolation to the others. Little research has integrated these factors to better predict innovative behaviors. This is especially true for field-based research in work contexts - much research is laboratory based. In this study, we look at the effects of an individual's work environment (in terms of levels of trust and connectivity) on a psychological state (thriving, which is composed of both cognitive and affective elements) which in turn is expected to enhance innovative behavior. In this way, we respond to Ward (2004) by examining cognitive, affective, and work context influences together in one study. We suggest that trust and connectivity may be important antecedents to innovative work behaviors through their impact on thriving.

\section{THEORETICAL BACKGROUND}

Before turning to thriving's relationship with innovative behaviors, the thriving construct must be differentiated from related constructs examined in prior research on innovation. One key psychological state examined in prior work is 
intrinsic motivation. Motivation is frequently defined as some variant on "the psychological forces that energize behavior" (e.g., Kanfer, 1990; Mitchell \& Daniels, 2003; Latham \& Pinder, 2005). Thriving captures this central tenant of motivation as it reflects an energetic force (i.e., vitality) that can direct work-related behavior (i.e., learning at and through work). However, thriving is not the same as intrinsic motivation, which is seen as the desire to do something based on the enjoyment of the behavior itself rather than relying on or requiring external reinforcement. Sonenshein, Dutton, Dutton, Spreitzer and Sutcliffe (2006) found that thriving narratives sometimes reflected intrinsic motivation (people were thriving when they were passionate about their work content or work relationships); at other times, these narratives emphasized achievement and recognition.

Individuals' innovative behaviors in the workplace are the foundation of any high-performance organization. This is especially apparent in a knowledge-based economy where intangible assets come to the forefront (Carmeli $\mathcal{E}$ Tishler, 2004) and play an ever more significant role in enhancing organizational competitiveness and "doing more with less". Given increased global competition over intangible talents, organizations need their employees' best ideas, regardless of task responsibility or level of organizational hierarchy. Employees are often on the front line with customers and see opportunities for change and improvement in work processes and procedures that are invisible to managers or others formally responsible for innovation in the organization. Indeed, a key to organizational survival is the process of creative destruction where an organization needs to weed out old competences and incessantly create new ones (Schumpeter, 1975). This process, however, is often enabled through employees who have more up-todate and nuanced knowledge about developments in the larger market (Foster $\mathcal{E}$ Kaplan, 2001) who can come up with and implement new ideas. Hence, "the study of what motivates or enables individual innovative behavior is critical" for future research (Scott $\&$ Bruce, 1994, p. 580).

As described above there is a great deal of research on ways in which cognitive, affect and work context can enable more creativity and innovative behavior. In terms of cognitive constructs, we know why cognitive biases, structures, and processes impact creativity (e.g., Finke, 1996; Friedman \& Forster, 2002; Mumford, Blair, Dailey, Leritz \& Osburn, 2004; Ward, 1994, 2004; Ward, Patterson \& Sifonis, 2004). Research suggests that creativity entails traits such intelligence and wisdom (Sternberg, 2001), creative self-efficacy (Carmeli \& Schaubroeck, 2007; Phelan $\mathcal{E}$ Young, 2003; Tierney $\&$ Farmer, 2002), unconscious thought processes (Martindale, 1981), and openness to experience (McCrae, 1987), all of which enhance the potential for innovative behavior. In terms of affect, researchers have found discrepant results in that both positive affect (Amabile, Barsade, Mueller, $\mathcal{E}$ Staw, 2005; Isen, Daubman \& Nowicki, 1987) and negative affect (George \& Zhou, 2002; Zhou $\&$ George, 2001) have at times been shown to contribute to creativity, indicating the importance of intervening variables.

Finally, there is a good body of literature detailing how and why work environments (e.g., Amabile, 1997; Amabile, Conti, Coon, Lazenby \& Herron, 1996; Gilson 
E Shalley, 2004; Hunter, Bedell, \& Mumford, 2007), and especially leadership (e.g., style and expectations, and influence tactics) (see Amabile $\mathcal{E}$ Gryskiewicz, 1989; Mumford, Scott, Gaddis, \& Strange, 2002; Scott $\&$ Bruce, 1994; Tierney, Farmer, \& Graen, 1999) affect individual and team creativity and innovation.

Our research adopts an integrative approach and examines how work environment and cognitive and affective aspects of thriving enhance innovative work behavior. In what follows, we develop a rationale to account for the ways in which thriving may lead individuals to display innovative behavior. We also articulate why trust in one's employer and connectivity may enable innovative behaviors through enhancement of thriving at work.

Prior conceptual work has suggested that strong relationships form the foundation upon which thriving endures. Spreitzer et al. (2005) hypothesized that a climate of trust and respect and the development of relational resources are important enablers of thriving at work. Only one study has empirically examined the relational foundations of thriving at work; it found that uncivil interactions (i.e., rudeness, disrespect) among colleagues are negatively related to thriving (Porath et al., 2007). But what positive elements of relationships enable thriving? An additional contribution of this paper is a deeper exploration of the relational foundations of thriving at work. The logic for these relationships is developed theoretically below. Figure 1 provides an overview of our theoretical framework.

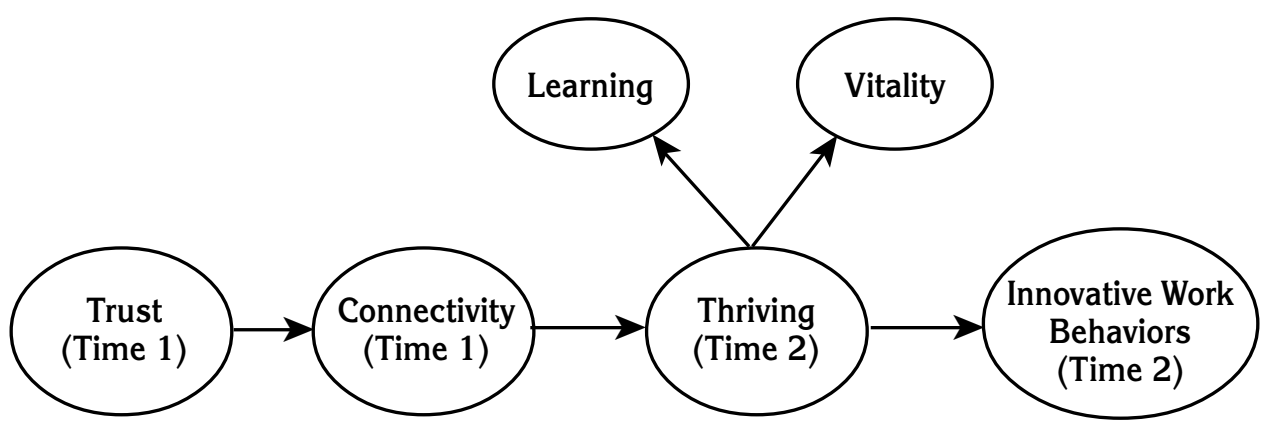

FIGURE 1. The Hypothesized Research Model.

\section{EMPLOYEE THRIVING AND INNOVATIVE BEHAVIORS AT WORK}

Why does thriving facilitate innovative behaviors at work? To answer this question we further conceptualize the idea of innovative work behavior, and then show theoretically how each dimension of thriving at work may facilitate innovative work behavior.

Individual innovative behavior in the workplace has three parts (Scott $\varepsilon$ Bruce, 1994). First, the individual recognizes a problem and comes up with new solutions and ideas. Second, the individual seeks ways to promote her or his solutions and ideas, and builds legitimacy and support both inside and outside the organization. Third, the individual makes the idea or solution concrete by producing a prototype or model of the innovation that can be experienced, applied and 
used within a work role, a group, or the organization as a whole (Kanter, 1988). As such, innovative work behavior encompasses all three parts ranging from when an individual recognizes a problem for which he or she generates new (novel or adopted from another context) ideas and solutions to when the individual works to promote and build support for them and finally produces an applicable prototype or model for the use and benefit of the organization or parts within it.

We reason that thriving may be an important catalyst of innovative behaviors at work. First, when individuals are learning and growing at work (the first dimension of thriving), they are in a favorable position to recognize problems and come up with new ideas. Amabile (1998) indicated that learning at work is necessary for building expertise (i.e., everything a person knows in the domain of work including technical, procedural, and intellectual know-how), which is a foundation for innovative behavior. It is through the learning process that individuals are likely to see the possibilities for new ways of doing and creating at work. Learning at work can also facilitate the other elements of innovative behaviors which are more about the implementation of innovative ideas. The new competencies and capabilities individuals are learning at and through work can increase their confidence to create legitimacy in the eyes of others, move beyond the status quo, and try new things.

Second, when individuals experience vitality in their work (the second dimension of thriving) they are more likely to have the energy and motivation to engage in innovative work. This energy, which involves the positive emotion experienced when a person is capable of and eager to engage in a particular behavior or undertake a task (Dutton, 2003; Quinn \& Dutton, 2005), is important for going beyond the normal roles and responsibilities to think and act creatively. Although prior work has found that negative affect can foster creativity (George $\mathcal{E}$ Zhou, 2002; Kaufman $\&$ Vosburg, 1997), recent research has explained these discrepant findings by showing that it is the arousal inherent in positive affect that explains the link between positive affect and creativity (Filipowitz, 2006). In addition, Kark and Carmeli (2009) have shown that vitality facilitates employee involvement in creative work. Innovative work is not passive - it requires promoting and championing ideas which takes energy. Innovative work is by nature a proactive kind of work behavior (Parker, Williams, \& Turner, 2006) where individuals seek out new technologies, processes, techniques, or even product ideas. Feeling capable of and eager to engage in innovative work behavior is especially crucial in the face of the skepticism and resistance that innovators face from others who believe that the status quo is acceptable or even preferable (Dutton, Ashford, O'Neill, \& Lawrence, 2001). Further, it requires psychological conditions that enable individuals to engage in innovative behaviors. For example, Vinarski-Peretz and Carmeli (in press) found that psychological conditions manifested by psychological safety, psychological meaningfulness and psychological availability, are key to motivating employees to engage in innovative behaviors.

When individuals experience positive moods at work, their creative thinking and problem solving skills are facilitated (Hirt, Levine, McDonald, \& Melton, 1997). 
Fredrickson's "broaden and build" theory of positive emotion (Fredrickson, 2003) provides a theoretical reasoning for why thriving facilitates innovative behaviors at work. In her research, Fredrickson (2001) found that when people experience positive emotions like vitality, they broaden their thought-action repertoires. Fredrickson (2001) introduces the term thought-action repertoire because positive emotions spark changes in cognitive activities which then contribute to behavioral tendencies - positive emotions themselves do not spark the behavioral tendencies. The term repertoire indicates the patterns of thoughts and actions that occur together in response to positive emotions. This broadening process may enable individuals to come up with fresh ideas. Positive emotions do more than broaden, however; they also build resources (Fredrickson, 2001). These include intellectual resources (which may help people be more creative and mindful), psychological resources (which enable more optimism and resilience which are also important in helping overcome the resistance from others) and social resources (which may help a person build legitimacy with others for the implementation of new ideas). This vitality may also be an indicator of one's level of intrinsic motivation, which has been found to be an important prerequisite for innovative behavior (Amabile, 1988). We thus hypothesize that:

Hypothesis 1. Thriving will be positively associated with innovative work behaviors.

\section{CONNECTIVITY AND THRIVING}

Connectivity is defined as relationships that are open and encourage generativity (Dutton \& Heaphy, 2003; Losada \& Heaphy, 2004). Connectivity in relationships enables people to see the diverse influences that come from others as opportunities for learning and growth at work. Connectivity involves seeing the value in relationships for learning new things, generating new ideas, and seeking opportunities to explore and grow. Connectivity implies a safe environment for people to try new things and take risks which facilitate learning and growth at and through work (Edmondson, 1999). Connectivity is also a key to broadening perspectives and building connections and hence is central to learning and ultimately to creativity (Hargadon, 2006).

Vitality and learning, the two dimensions of thriving, are deeply rooted in social systems that are connective (Spreitzer et al., 2005). For example, Miller and Stiver (1997) suggest that the development of the self occurs through dynamic interactions with others. Their relational view of self-development describes how vitality - what they term "zest" - comes from relational connections with others. People feel vital when they have deep, generative relationships with others. Second, with respect to learning, many scholars claim that learning does not take place solely in the individual mind or in isolation from others (Wenger, 1998). Instead, learning occurs in social connections - through interactions with others in the doing of work, talking about work, and observing others doing their work (Brown $\&$ Duguid, 1991). Learning takes place through the social connections 
that bind us together with others (see Carmeli, Brueller, E Dutton, 2009) - we are sources of new ideas and knowledge for each other.

More specific to thriving research, Spreitzer et al. (2005) suggest that thriving is more likely to occur when individuals heedfully relate to others (a construct that is highly consistent with connectivity). When individuals relate heedfully, they act in ways that demonstrate that they understand how their own job fits with the jobs of others to accomplish the goals of the system. When individuals relate heedfully, they are more able and likely to help others and provide social support. Helping others and providing social support often increase affective (Carlson, Charlin, \& Miller, 1988) and physiological (Brown, Nesse, Vinokur, \& Smith, 2003) energy - in line with the vitality dimension of thriving. Moreover, connectivity may promote a sense of learning, the second dimension of thriving, as well. As coworkers enable each other to be open to new approaches, they are likely to learn from the strategies and approaches used by these coworkers (Bandura, 1986). Consequently, connectivity in relationships can enable individuals to acquire and use new skills, and hence experience learning at and through work (Parker $\mathcal{E}$ Sprigg, 1998). Thus, we suggest that:

\section{Hypothesis 2: Connectivity will be positively associated with thriving.}

\section{CONNECTIVITY, THRIVING, AND INNOVATIVE BEHAVIOR}

We expect that connectivity will not only have an effect on thriving, it will also, in turn, be associated with innovative work behavior. In terms of a direct relationship between connectivity and innovative behavior, Amabile (1998) reported that people are more creative when they have more supportive connections with those they work with because they feel psychologically safe to try new things. Amabile (1998) also found that connectivity with one's supervisor (i.e., encouragement from supervisors that one's work is valued and matters to the organization) is associated with creative behavior in subordinates. Supervisors build connectivity with their subordinates when they show empathy for subordinates' feelings, help alleviate stressful situations, create an atmosphere free of threatening evaluations, and demonstrate openness to subordinates' ideas (Albrecht $\mathcal{E}$ Hall, 1991; Amabile, 1997; Delbecq \& Mills, 1985). Kanter (1983) further found that connectivity with one's manager (through participative, collaborative management and open communication) was important for innovation in organizations. All of these findings are consistent with the idea that more connectivity in work relationships should be related to innovative behavior.

While there is evidence to suggest a direct link between connectivity and innovative work behavior, we propose that thriving will mediate the link between connectivity and innovative work behavior. The generativity inherent in connectivity (i.e., relationships help generate new ideas and seek out new opportunities) enables people to learn from each other - the first dimension of thriving. Moreover, because connectivity reflects relationships that are open to new ideas and diverse influences, this generativity will produce vitality in individuals - the 
second dimension of thriving. People are likely to get fired up when they are embedded in open relationships where people listen to each other and share ideas and information with each other. Thus, we hypothesize that:

\section{Hypothesis 3. Thriving will mediate the relationship between connec- tivity and innovative behavior.}

\section{TRUST, CONNECTIVITY, AND THRIVING}

Trust is defined as "one's expectations, assumptions, or beliefs about the likelihood that another's future actions will be beneficial, favorable, or at least not detrimental to one's interests" (Robinson, 1996, p. 576). As a core relational construct, trust is often conceptualized in terms of one's perceived risk of vulnerability within a connection (Rousseau, Sitkin, Burt, $\mathcal{E}$ Camerer, 1998). Thus, trust is conceptualized as "the willingness of a party to be vulnerable to the actions of another party" (Mayer, Davis, \& Schoorman (1995, p. 712) and an expression of confidence by a party that his or her vulnerability will not be exploited and that he or she will not be harmed by the behaviors or actions of the other party (Blau, 1964; Deutsch, 1958; Jones \& George, 1998; Kramer, 1999; Robinson, 1996; Zand, 1972). Trust and connectivity are both relational mechanisms by which individuals may be encouraged to engage in work tasks. Indeed, both trust and connectivity are important for increasing the emotional space needed for creativity (Losada, 1999). As observed by Losada and Heaphy (2004), team members showing appreciation and encouragement to their teammates created emotional spaces that were expansive and opened up possibilities for action and creativity. However, when members faced an atmosphere charged with distrust and cynicism and there was a low level of connectivity in the relationships between team members, a very restrictive emotional space was created and teams achieved relatively low performance.

However, trust and connectivity are conceptually distinct constructs. Trust manifests the degree of one's vulnerability to another (Zand, 1972) whereas connectivity does not explicitly specify vulnerability in a person's relationship with another person. In addition, whereas connectivity indicates relationships that are generative, one may believe that his or her relationships with another person are characterized by a high level of trust, yet still not feel generativity.

We suggest that trust in one's employer will be associated with more thriving at work directly, as well as indirectly through, or mediated by, connectivity. In terms of a direct relationship, trust is likely to enhance vitality (one dimension of thriving). When individuals develop trust in their organization, their level of vitality to engage in work tasks is likely to increase, contributing to the vitality dimension of thriving. Whereas a trusting organizational environment augments positive feelings and the vitality to participate and contribute to others and the organization, a mistrusting environment grates on people (Mishra, 1996). People who experience mistrust and disrespect report psychological distress (Cortina, Magley, Williams, $\mathcal{E}$ Langhout, 2001) and negative emotional effects (Pearson $\mathcal{E}$ Porath, 2005). Negative emotions and attitudes from a rude or disrespectful environment 
ultimately decrease vitality (Porath $\&$ Erez, 2008). Trust in one's employer is also likely to enable more learning at and through work (the second dimension of thriving) because people recognize the psychological contract (Rousseau, 1989; Rousseau \& Parks, 1994) and feel they have the support and encouragement of their employer to take risks and try new things.

We also posit an indirect relationship; namely that connectivity will mediate or explain why trust is associated with more thriving at work. Robinson (1996) theorized that trust in one's employer (organization) is important because it creates a psychological contract or is negatively related to a psychological breach. We argue that trust cultivates both openness and generativity, which are manifestations of connectivity. Trust cultivates an open space where people can exchange ideas, accept the different, as well as a space where they can generate and implement new ideas.

Trust also enhances psychological safety (Edmondson, 2004; Kahn, 1990; May, Gilson, $\&$ Harter, 2004) which underpins notions of connectivity. Psychological safety is rooted in relationships characterized by a high level of trust (Edmondson, 1999). Studies have also linked trust and psychological safety to learning, which is one dimension of thriving at work. When individuals do not have trust in their employer, they tend to either shut down or use up valuable cognitive assets while trying to make sense of the environment or how they should respond (Mishra, 1996). Thus, mistrustful environments inhibit openness and generativity and can drain emotional and cognitive resources necessary for learning at and through work(Porath E Erez, 2008). Trust can enhance feelings of efficacy and capability at work (Spreitzer $\mathcal{E}$ Mishra, 1999), thus allowing individuals (and groups) to engage in more proactive and risk taking behaviors (Mayer, Davis, \& Schoorman, 1995) which can facilitate learning at and through work (Bunderson $\&$ Sutcliffe, 2002; Hargadon, 1999). Thus, we posit that trust in one's employer is likely to facilitate openness and generative relationships with other members in the organization which in turn will help the individual to thrive in his or her work.

Hypothesis 4. Trust in one's employer will be positively related to thriving.

Hypothesis 5. Connectivity will mediate the relationship between trust and an employee's sense of thriving.

\section{$M \in T H O D$ \\ SAMPLE AND PROCEDURE}

Two hundred and thirty employees were asked to participate in this study. The employees came from different organizations in different industries in Israel. Participants were asked to complete a structured survey at two points in time, with a lag of three weeks between Time 1 and Time 2. We chose a time lag of three weeks because we wanted to examine how trust and connectivity at one point in time influenced thriving at a later point in time - but not have so much time elapse that the participants' life circumstances would have changed in any significant way. Three weeks seemed long enough for respondents not to remember their original answers in responding to the thriving and innovative work behavior 
measures. The average time for completing each questionnaire was about 15 minutes. Respondents selected a unique and anonymous identifier so that we could match the same respondent's completed questionnaires from Time 1 with that from Time 2, and to preserve anonymity.

We received 194 surveys. However, because of missing data we focused on only the 172 surveys of employees who completed the two surveys, representing a response rate of $74.78 \%$. The missing cases were due to people failing to respond to one or items in the survey. The respondents' average age was 32.73 years (s.d. 8.43), and their average job tenure was 5.16 years (s.d. 6.02). Fiftyone percent of the respondents were female, and 55 percent were living with a spouse. Thirty-one percent of the participants held a high school or diploma degree, $50.8 \%$ held a Bachelor's Degree, while the remainder of the participants held a Master's degree or above.

\section{MEASURES}

The Appendix presents all the items for the survey variables.

Innovative work behaviors. We used the 6-item scale developed by Scott and Bruce (1994) designed to assess employee innovative behaviors at work. Employees were asked to report on the extent to which they engage in and display innovative behaviors at work. Sample items were (1) "I seek out new technologies, processes, techniques, and/or product ideas at work" and (2) "I generate creative ideas at work". Responses were made on a five-point Likert-type scale ranging from $1=$ "not at all" to 5 = "to an exceptional degree". Results of factor analysis on all measurement items used in this study showed that all items pertaining to innovative work behavior loaded onto one factor with an eigenvalue of 4.61 , accounting for 14.88 percent of the variance and having factor loadings ranging from .74 to .82 .

Thriving. Thriving refers to a process of human growth manifest in both learning and vitality (Spreitzer, Sutcliffe, Dutton, Sonenshein, E Grant, 2005). Consistent with this definition, we used three items to measure learning at and through work (sample item: "To what extent do you learn new things at work?") and 8 items used in Atwater and Carmeli's (2009) study to measure feelings of vitality or energy at work (sample item: "I feel active and energetic at work"). Responses were made on a five-point Likert-type scale ranging from $1=$ "not at all" to 5 = "to an exceptional degree". Results of factor analysis on all measurement items used in this study showed that all items pertaining to thriving loaded onto two factors. The first factor consisted of the vitality items, with an eigenvalue of 5.78, accounting for 52.56 percent of the variance and having factor loadings ranging from .80 to .86 . The second factor consisted of the three learning items, with an eigenvalue of 2.85, accounting for 25.92 percent of the variance and having factor loadings ranging from .81 to .92 . However, because learning and vitality are both elements of the higher order construct thriving, like Spreitzer, Cobb and Stevens (2007), we modeled thriving as a second-order construct which is manifested by two firstorder constructs: learning and vitality (see Figure 1 ). The Cronbach's alpha for thriving was .94 . 
Connectivity. To measure connectivity, we found the concept of high quality connection to be relevant (Losada, 1999; Losada \& Heaphy, 2004). This concept indicates relationships reflecting generativity and openness to new ideas and influences (Dutton \& Heaphy, 2003). To assess the degree of connectivity members have with each other in the organization we constructed four items to measure openness in a relationship (sample item: "We have very open relationships") and three items to measure the degree to which a relationship is generative (sample item: "The relationships we have enable us to generate new things"). Responses were made on a five-point Likert-type scale ranging from $1=$ "not at all" to $5=$ "to an exceptional degree". Results of a factor analysis on all measurement items used in this study showed that all items pertaining to connectivity at work loaded onto one factor with an eigenvalue of 4.95 , accounting for 15.96 percent of the variance and having factor loadings ranging from .68 to .78. The Cronbach's alpha for this measure was .93.

Trust in one's employer. To assess trust in one's employer, we used four items of the scale developed and validated by Robinson (1996). Respondents were asked to report on the extent to which there is trust in the relationship between them and their employer. A sample item is "In general, I believe my employer's motives and intentions are good." Responses were made on a five-point Likert-type scale ranging from 1 = "not at all" to 5 = "to an exceptional degree". Results of factor analysis on all measurement items used in this study showed that all items pertaining to trust loaded onto one factor with an eigenvalue of 3.11, accounting for 10.03 percent of the variance and having factor loadings ranging from .73 to .85 . The Cronbach's alpha for this measure was .87.

Control Variables. We controlled for organizational tenure because the work domain expertise that comes with tenure (Oldham \& Cummings, 1996; Tierney $\varepsilon$ Farmer, 2004) may account for variance in innovative behaviors. We also controlled for age because previous research suggests that older workers who have been with a company for some time often are less innovative in their work people tend to become set in their ways over time (Janssen, 2004). In addition we controlled for educational level since previous research indicates that people with lower educational attainment may have less positive attitudes toward their work. Following Carmeli and Schaubroeck's (2007) study, we also controlled for gender differences ( $1=$ Female, $0=$ Male $)$ because they may account for variation in the degree to which men and women are involved in innovative work. Finally, although previous research has suggested that some level of creative and innovative behavior is required for almost any job (Shalley, Gilson, \& Baum, 2000; Unsworth, 2001), others (Gilson \& Shalley, 2004) note the need to control for jobs that require a high level of creative and innovative behaviors by constructing a dummy variable (jobs that require high level of innovative behaviors $=1$ and jobs that require low level of creative and innovative behaviors $=0$ ). We obtained information about the jobs held by each participant. Consistent with previous research, managers, engineers, programmers, analysts, physicists, marketing employees, physicians and consultants and TV content specialists were considered as having jobs that require more creativity and innovation at work. 


\section{Dato Anoluses}

To estimate the research model, we used structural equation modeling (SEM) (Bollen, 1989), employing AMOS 6 software (Arbuckle, 2003). We followed the two-step approach to SEM outlined by Anderson and Gerbing (1988) in which construct validity was assessed using confirmatory factor analysis followed by a comparison of a sequence of nested structural models. To overcome problems associated with using a single goodness-of-fit index in SEM (Medsker, Williams, $\varepsilon$ Holahan, 1994), we used several goodness-of-fit indices in assessing the fit of the research model (Joreskog $\&$ Sorbom, 1993; Kline, 1998). These fit indices include the Chi-square statistic divided by the degrees of freedom $\left(\chi^{2} / \mathrm{df}\right)$; Incremental Fit Index (IFI), Comparative Fit Index (CFI), Tucker-Lewis coefficient (TLI), and Root Mean Square Error of Approximation (RMSEA). As suggested in the literature (Joreskog \& Sorbom, 1993; Kline, 1998), the following criteria of goodness-of-fit indices were used to assess the model-fit: the $\chi^{2} / \mathrm{df}$ ratio is recommended to be less than 3; the values of RFI, NFI, CFI, and TLI are recommended to be greater than .90; RMSEA is recommended to be up to .05, and acceptable up to 08 .

\section{RESULTS}

The means, standard deviations, reliabilities and correlations among the research variables are presented in Table 1 . Consistent with our hypotheses, the bivariate correlations indicate that innovative work behavior is positively related to thriving, $(r=.66, p<.001)$, connectivity $(r=.49, p<.001)$, and trust $(r=.27, p$ $<.001)$. The results also show that trust is positively associated with both connectivity $(r=.56, p<.001)$ and thriving $(r=.44, p<.001)$. We also found that there is a positive relationship between connectivity and thriving $(r=.68, p<.001)$

TABLE 1. Means, Standard Deviations (SD), and Correlations.

\begin{tabular}{|c|c|c|c|c|c|c|c|c|c|c|}
\hline & Mean & SD & 1 & 2 & 3 & 4 & 5 & 6 & 7 & 8 \\
\hline $\begin{array}{l}\text { 1. Gender } \\
\text { (1=Female) }\end{array}$ & - & - & - & & & & & & & \\
\hline 2. Age & 32.73 & 8.43 & -.13 & - & & & & & & \\
\hline 3. Education & 2.66 & 1.03 & -.04 & -.03 & - & & & & & \\
\hline $\begin{array}{l}\text { 4. Organizational } \\
\text { tenure }\end{array}$ & 5.16 & 6.02 & -.12 & $.65^{* * *}$ & $-.27^{* *}$ & - & & & & \\
\hline 5. Trust & 3.70 & .92 & -.11 & -.07 & $.18^{*}$ & -.10 & $(.87)$ & & & \\
\hline 6. Connectivity & 3.66 & .80 & $-.17^{*}$ & -.01 & $.22^{* *}$ & -.05 & $.56^{\text {*t* }}$ & $(.93)$ & & \\
\hline 7. Thriving & 3.48 & .84 & $-.21^{* *}$ & .06 & $.16^{*}$ & .04 & $.44^{* * *}$ & $.68^{* * * t}$ & $(.94)$ & \\
\hline $\begin{array}{l}\text { 8. Innovative work } \\
\text { behaviors }\end{array}$ & 3.12 & .89 & $-.32^{* * * t}$ & .14 & .14 & .08 & $.27^{*+* t}$ & $.49^{* * *}$ & $.66^{* * *}$ & $(.92)$ \\
\hline
\end{tabular}

Notes: $N=172$, Alpha reliabilities appear in parentheses.

"p d". .05, "** $p \mathrm{~d} " .01,{ }^{* * *} p \mathrm{~d}$.001 


\section{Preliminarụ Anolusses}

Prior to testing the proposed model, we sought to show evidence of the construct validity of the exogenous and endogenous variables. Using confirmatory factor analysis (CFA), a second-order measurement model was tested to assess whether each of the measurement items would load significantly onto the scales with which they were associated. The results of the overall CFA showed acceptable fit with the data; a Chi-square of 889.3 with 349 degrees of freedom, and other goodness-of-fit statistics (CFI = .88; IFI = .88; TLI = .86; RMSEA $=.08$ ) were obtained. Standardized coefficients from items to factors ranged from .72 to .92 . In addition, the results for the CFA indicated that the relationship between each indicator variable and its respective construct was statistically significant $(p<$ .01 ), establishing the posited relationships among indicators and constructs, and thus, convergent validity (see Hair et al., 1998).

We also tested two alternative factor analyzed models. First, we specified a two-factor model where the observed items of both trust and connectivity (both measured at Time 1) were loaded onto one latent factor and the observed items of both thriving and innovative work behaviors (both measured at Time 2) were loaded onto another latent factor. This model tests whether a common method at the two different points in time captures the variation in the measures. The results of this two-factor model generated the following fit indices: a Chi-square of 1934.71 with 353 degrees of freedom, and CFI = .65; IFI $=.65$; NFI = .61; TLI = .591; RMSEA $=.15$. We also explored a one-factor model where all observed items were loaded onto the same latent variable. This model is expected to capture the extent of common method variance overall. The results of the one-factor model yielded the following fit indices: a Chi-square of 2097.3 with 354 degrees of freedom, and $\mathrm{CFI}=.61 ; \mathrm{IFI}=.61 ; \mathrm{NFI}=.57 ; \mathrm{TLI}=.58 ; \mathrm{RMSEA}=.16$. The relatively poor fit of both of these alternative models indicates that the hypothesized second-order measurement model fits the data well and thus we could move forward with the tests of our hypotheses.

\section{Model Comparisons and Hupothesis Tests}

Trust, connectivity, thriving and innovative work behaviors are multi-item latent constructs, and therefore we used maximum likelihood SEM to test the model. We evaluated the fit using the various fit indices described above as well as the significance of the completely standardized path estimates (Joreskog $\mathcal{E}$ Sorbom, 1993; Bollen, 1989).

We first compared the hypothesized research model shown in Figure 1 (which we will refer to as Model 1) with the same model with two additional paths from (a) trust to thriving and (b) connectivity to innovative work behaviors (which we will refer to as Model two). Thus, we compared the hypothesized fully mediated relationship (Model 1) to an alternative partially mediated set of relationships (Model 2). In addition, we compared Model one with a model in which we drew, in addition to the added paths of Model 2, a path from trust to innovative work behaviors (which we will refer to as Model 3). 


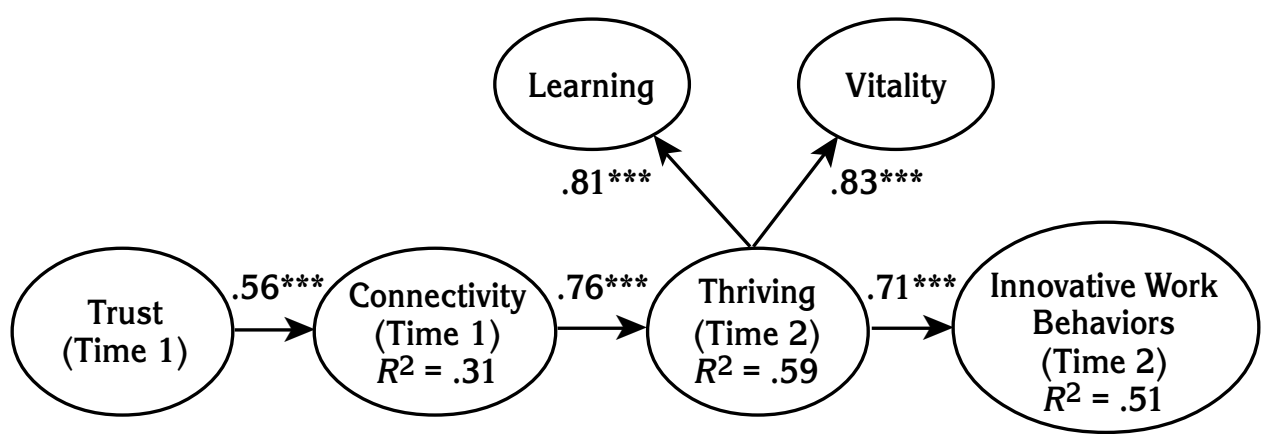

Ovals show latent variables. For clarity, the indicators (items) of the variables are not shown. Statistics are standardized parameters.

FIGURE 2. Results of the Hypothesized Model: Relationships between Trust, Connectivity, Thriving, and Engagement in Innovative Work.

The results of the research model (Model 1) in Figure 2 showed good fit with the data; a Chi-square of 625.98 with 346 degrees of freedom, and other goodness-of-fit statistics (CFI $=.94 ;$ IFI $=.94 ; \mathrm{TLI}=.93 ; \mathrm{RMSEA}=.06$ ) were obtained. Values of .90 and above on TLI is desirable, and the value of .06 on RMSEA provides evidence that the model fits the data well. The results indicate significant paths from (a) trust to connectivity $(.56, p<.001)$, (b) connectivity to thriving $(.76, p<.001)$, and (c) thriving to innovative work behavior $(.71, p<.001)$. The model explained 51 percent of the variance in innovative work behaviors.

The results of Model 2, which posited partial mediation by adding two paths from (a) trust to thriving and (b) connectivity to innovative work behaviors, yielded similar goodness-of-fit statistics: a Chi-square of 624.31 with 344 degrees of freedom; $\mathrm{CFI}=.94 ; \mathrm{IFI}=.93 ; \mathrm{TLI}=.93 ; \mathrm{RMSEA}=.06$. However, the two new paths from (a) trust to thriving and (b) connectivity to innovative work behaviors were not significant $(.003, p=.97 ;-.18, p=.24$, respectively). Thus, the more parsimonious Model 1 was preferred.

Next, we also compared Model 1 to the second alternative non-mediated model (Model 3) in which three additional paths were specified (a) trust to thriving, (b) trust to innovative work behaviors, and (c) connectivity to innovative work behaviors. A Chi-square of 622.503 with 343 degrees of freedom and other fit-of-indices $(\mathrm{CFI}=.94 ; \mathrm{IFI}=.94 ; \mathrm{TLI}=.93 ; \mathrm{RMSEA}=.06)$ were obtained. These goodness-offit indices are similar to those of Model one. However, none of the newly added paths were significant: (a) trust to thriving $(.05, p=.57)$, (b) trust to innovative work behaviors $(-.12, p=.18)$, and (c) connectivity to innovative work behaviors $(-.12, p=.46)$. We accordingly accepted the theoretical model (Model 1$)$, which is shown in Figure 1, as the most parsimonious (Anderson $\mathcal{E}$ Gerbing, 1988). We also used Model 1 as the benchmark (e.g., comparison group) for all other models and compared chi-square differences. Results indicate that the differences between Model 1 and both alternative models were not significant. In addition, as explained below, consistent with rules of model parsimony, the data of Model 1 support full mediation and thus this model was selected. 
The results also meet the guidelines for testing mediation as outlined by Baron and Kenny (1986) and more recently modified and stipulated in Kenny, Kashy and Bolger's (1998) paper. Following MacKinnon et al. (2002), we simultaneously tested the significance of both the path from an initial variable to a mediator and the path from the mediator to an outcome as this approach provides, relative to other approaches, the best balance of type I error rates and statistical power.

As described above, the hypothesized mediation model (Figure 1) showed that all paths were significant: (1) the path from trust to connectivity $(.56, p<.001)$, (2) the path from connectivity to thriving $(.76, p<.001)$, and (3) the path from thriving to innovative work behaviors $(.71, p<.001)$. The findings of Model 3 indicate that the paths from (1) trust to thriving $(.05, p=.57),(2)$ trust to innovative work behaviors $(-.11, p=.18)$, and (3) connectivity to innovative work behaviors $(-.12, p=.46)$ were not significant while the specified mediators, (1) connectivity for the relationship between trust and thriving and (2) thriving for the relationship between connectivity and innovative work behaviors, remained significant $(.76, p<.001$, and $, 79, p<.001)$. Hence, these results support Hypothesis 3 , which posited that the relationship between connectivity and employee innovative work behaviors would be mediated by thriving, as well as Hypothesis 5 , which predicted that connectivity would mediate the relationship between trust and employee sense of thriving.

To further evaluate our mediation model, we followed Shrout and Bolger's (2002) recommendation to conduct bootstrap analyses in order to provide a more rigorous test of whether the mediated effects found in the model were statistically significant. The analysis tested the mediating effect of (1) connectivity in the relationship between trust and thriving, and (2) thriving in the relationship between connectivity and innovative work behaviors. The results of 1,000 usable bootstrap samples that were obtained show that none of the 1,000 usable bootstrap samples had a value less than zero, indicating that the mediated effects observed earlier were significant (Bollen-Stine bootstrap $p=.001$ ).

In addition, we tested the effects of the control variables on the innovative work behaviors in a regression analysis. The results indicate no significant effect of age, tenure, education or jobs that require a high level of innovation on innovative work behaviors. However, we found a significant effect of gender on innovative work behaviors, suggesting that compared to women, men reported a higher level of engagement in innovative work.

\section{Additional Anoluses}

We also contrasted the model across jobs that require more and less creativity. To test these potential differences we created a dummy variable $(1=$ more creative job and $0=$ less creative job). Because of this split two small samples were created. Thus, we used path analysis to test our model.

In the sample consisting of employees in more creative jobs $(N=60)$, the results of the path analysis model of Trust $\rightarrow$ Connectivity $\rightarrow$ Thriving $\rightarrow$ Innovative Work Behaviors, when controlling for age and tenure, showed good fit with the data. A Chi-square of 10.4 with 9 degrees of freedom and other fit-of-indices $(\mathrm{CFI}=.92 ; \mathrm{IFI}=.97 ; \mathrm{TLI}=.96 ; \mathrm{RMSEA}=.05)$ were obtained. The relationship 
between trust and connectivity was positive and significant $(.44, p<.001)$. Connectivity was significantly related to thriving $(.45, p<.001)$, and thriving was significantly associated with innovative work behaviors $(.52, p<.001)$.

In the sample consisting of employees in less creative jobs $(N=112)$, the results of the path analysis model of Trust $\rightarrow$ Connectivity $\rightarrow$ Thriving $\rightarrow$ Innovative Work Behaviors, when controlling for age and tenure, showed good fit with the data. A Chi-square of 11.2 with 9 degrees of freedom and other fit-of-indices $(\mathrm{CFI}=.99 ; \mathrm{IFI}=.99 ; \mathrm{TLI}=.98 ; \mathrm{RMSEA}=.045)$ were obtained. The relationship between trust and connectivity was positive and significant $(.57, p<.001)$. Connectivity was significantly related to thriving $(.69, p<.001)$, and thriving was significantly associated with innovative work behaviors $(.61, p<.001)$.

The findings of these two separate models indicate the importance of trust and connectivity in fostering thriving, which, in turn, is a key to facilitating innovative work behaviors.

\section{DISCUSSION}

In this study, we examined the relationship between trust, connectivity (both measured at Time 1) and thriving and innovative work behaviors (both measured at Time 2). To summarize the findings, the SEM results indicate a sequential mediation model in which connectivity mediates the relationship between trust and thriving, and thriving mediates the relationship between connectivity and innovative work behaviors. These findings support the posited research model hypotheses advanced in the theoretical part of this paper.

\section{THEORETICAL IMPLICATIONS}

A key contribution of the current study to the literature is our attempt to bring contextual, cognitive, and affective influences on innovative behavior into a single theoretical model. We provide the first examination of relational antecedents of thriving and their implications for innovative work behaviors. In doing so, we respond to recent calls by Shalley, Zhou and Oldham (2004) for research which examines how mediators (beyond the traditional focus on intrinsic motivation) impact on creative/innovative behaviors at work. These authors explicitly emphasized the need to examine positive affect as one key mediator (2004, p. 945). Our work indeed captures positive affect (i.e., vitality) as one dimension of thriving. In particular, our study and its findings contribute to the literature on thriving, innovative work behaviors, and relational mechanisms at work.

First, our study sheds light and extends previous studies on the outcomes of employee feelings of thriving at work. Prior research on thriving outcomes has focused on in-role outcomes such as task performance as well as extra-role performance such as organizational citizenship behaviors (Porath et al, 2007). However, the current study differs from these previous studies in that we delineate why thriving may also enable more proactive, risk-full behaviors such as creativity and innovation in the workplace. Thriving at work not only enables employees to get their job done well but also increases their capacity to display innovative work behaviors - bringing new ideas to the table, gaining buy-in for these ideas, and creating momentum for implementation. 
Second, the present research also expands the body of knowledge on innovative work behaviors by theorizing a more complex model of work behaviors. Although previous research has indicated that both trust and connectivity are important relational facilitators of innovative and creative behaviors at work, we found that as expected, there is a sequential relationship between trust, connectivity, thriving and innovative work behaviors. Specifically, our findings suggest that there are indirect relationships between trust and thriving (through connectivity) as well as between connectivity and innovative work behaviors (through thriving). This taps both relational and psychological antecedents in explaining the degree to which individuals engage in and display innovative work behaviors.

Third, extant theory and research have tended to focus on the effect of either cognitive antecedents such as creative self-efficacy (Carmeli $\mathcal{E}$ Schaubroeck, 2007; Phelan E Young, 2003; Tierney E Farmer, 2002) or affective antecedents (Amabile et al, 2005; Madjar et al, 2002) on creative behaviors at work. We extend this body of research because our study adds credence to the idea that cognitions focused on learning and emotional vitality or energy play an important role in fueling creative and innovative behaviors at work.

Last, our research contributes to a better understanding of the implications of trust in one's employer in augmenting connective relationships, thriving and innovative behaviors at work. Although we did not specifically assess psychological contract, our study suggests that trust in one's employer creates a psychological contract that augments generative relationships with colleagues (i.e., connectivity). This connectivity in relationships between colleagues in an organization is an important factor affecting individual's thriving, which, in turn, facilitates innovative behaviors in the workplace.

\section{UIMITATIONS AND FUTURE RESEARCH DIRECTIONS}

Our study is not without limitations. Using structured survey and self-reports may lead common method bias. It may be argued that employees may espouse theory about the work context and psychological conditions that enable innovative behaviors and thus respond in kind. We have taken several steps to alleviate this concern and performed tests in order to evaluate the extent to which this common method bias problem is severe in the current study. First, our data were collected at two different points in time to attempt to mitigate this problem (Podsakoff, MacKenzie, Lee and Podsakoff (2003). Second, we carried out a confirmatory factor analysis (i.e., the Harman one-factor test) on all items constituting the research measures of the model. The results of this analysis showed clear support for the distinction of the constructs in our model, indicating that no dominant factor has emerged and thus may suggest that response biases may not be severe. Third, we further tested whether there are differences in the level of innovative work behaviors that can be attributed to demographic characteristics (considered as stable and objective data) such as age, tenure and education, and found no significant differences. The only difference we found is between women and men. Fourth, we have tested whether the data were inflated and thus generate problems of multicollinearity. The results of this test indicate that none of the 
independent variables had VIFs greater than the stringent cutoff of 2.5 (the more lenient cutoff is 10) ( $c f$. Belsley, Kuh, $\mathcal{E}$ Welsch, 1980). Hence, while we cannot rule out the possibility of common method bias, the aforementioned procedures and tests indicate that this issue is not severe in this study. Nevertheless, future research should further alleviate this concern by employing objective measures of innovative work behaviors or at least relevant others' assessments of innovative behavior.

A second limitation is that we did not have a more extensive set of control variables. It is possible that one or more of our constructs could be susceptible to social desirability bias. Furthermore, while we did include a dummy variable for the creativity required in the types of jobs employees held, we had no measure of creative climate. Although we believe that trust and connectivity are key elements of a creative climate, we acknowledge that a creative climate includes other factors such as the organizational values around creative behavior, the evaluation process, rewards for creative output, and group/peer support. Future research should control for these broader elements of creative climate.

A third limitation is the issue of causality. Innovative work behaviors may contribute to people's thriving because creative work tends to be more fun and nonroutine. It may also be the case that when people are thriving at work, they enable more trust and connectivity with those with whom they work. Future research should explore more thoroughly the nature of causality, and the causal direction we argue is inherent to our model, by conducting longitudinal analyses where all variables are measured at multiple points in time. This would clarify the nature of the causal relationships among the variables.

Except for gender, we did not find significant effect of demographic characteristics on innovative behaviors. Our study indicates that men tend to be more engaged in innovative behaviors. This may be explained by the work context in which participants work and the norms and expectations set up by their managers. It might be that in the Israeli cultural context that men are expected to be more innovative at work. This issue, however, needs further research attention in other settings.

\section{MANAGERIAL IMPLICATIONS}

Today's work environment requires more ingenuity and fresh ideas from employees. From new product ideas to better ways to respond to customer needs, to improvements in processes in the workplace, employers demand more of their employees' creativity and innovation (Leana E Barry, 2000; Lovelace, Shapiro, E Weingart, 2001). Organizations can no longer survive by doing more of the same. While we often hear about the impressive benefits and perks that companies like Google or SAS offer their employees to motivate creative and innovative behaviors, this research suggests that there may be cheaper and more sustainable ways to enable employee innovative behaviors. Generative relationships that enable human thriving at work (i.e., learning and vitality) are less expensive alternatives than high priced gourmet meals, workplace concierges, or in-house masseuses.

Other research suggests that younger employees may expect if not demand more opportunities to thrive in their work. Recent commentaries on "millennial" 
employees (those born before 1980) suggest they are looking for work to be a place where they are appreciated and enabled to thrive but not at the expense of their home life or interests. Younger employees may be less interested in career advancement and more concerned with opportunities to grow and develop while having fun at the same time. Thus, these findings on thriving in relation to innovative behavior provide some insights for companies on how to respond to the needs of younger employees.

\section{$R \in F \in R \in N C \in S$}

ALBRECHT, T. L. E HALL, B. J. (1991). Facilitating talk about new ideas: The role of personal relationships in organizational innovation. Communication Monographs, 58, 273-288.

AMABILE, T. M. (1983). The social psychology of creativity. New York: Springer-Verlag.

AMABILE, T. M. (1988). A model of creativity and innovation in organizations. In B. M. Staw $\&$ L. L. Cummings (Eds.), Research in organizational behavior (Vol. 10, pp. 123-167). Greenwich, CT: JAI Press.

AMABILE, T. M. (1997). Motivating creativity in organizations: On doing what you love and loving what you do. California Management Review, 40, 39-58.

AMABILE, T. M. (1998). How to kill creativity. Harvard Business Review, 76, 77-87.

AMABILE, T. M., BARSADE, S. G., MUELLER, J. S., E STAW, B. M. (2005). Affect and creativity at work. Administrative Science Quarterly, 50, 367-403.

AMABILE, T. M., CONTI, R., COON, H., LAZENBY, J., \& HERRON, M. (1996). Assessing the work environment for creativity. Academy of Management Journal, 39(5), 1154-1184.

AMABILE, T., \& GRYSKIEWICZ, N. D. (1989). The creative environment scales: Work environment inventory. Creativity Research Journal, 2, 231-253.

ANDERSON, J. C., \& GERBING, D. W. (1988). Structural equation modeling in practice: A review and recommended two-step approach. Psychological Bulletin, 103, 411-423.

ARBUCKLE, J. L. (2003). Amos 5.0 Update to the Amos User's Guide. Chicago, IL: Smallwaters Corporation.

ATWATER, L., \& CARMELI, A. (2009). Leader-member exchange, feelings of energy and involvement in creative work. The Leadership Quarterly, 20, 264-275.

BANDURA, A. (1986). The social foundations of thought and action. Prentice-Hall: Englewood Cliffs, NJ.

BARRON, R. M., E KENNY, D. A. (1986). The moderator - mediator variable distinction in social psychological research: Conceptual, strategic, and statistical considerations. Journal of Personality and Social Psychology, 51, 1173-1182.

BELSLEY, D. A., KUH, E., \& WELSCH, R. E. (1980). Regression Diagnostics: Identifying Influential Data and Sources of Collinearity. New York: John Wiley and Sons.

BLAU, P. M. (1964). Exchange and power in social life. New York: Wiley.

BOLLEN, K. A. (1989). Structural equations with latent variables. New York: Wiley.

BROWN, J. S., \& DUGUID, P. 1991. Organizational learning and communities of practice: Towards a unified theory of working, learning and innovation. Organization Science, 2, 40-57.

BROWN, S. L., NESSE, R. M., VINOKUR, A. D., E SMITH, D. M. (2003). Pro-viding social support may be more beneficial than receiving it: Results from a prospective study of mortality. Psychological Science, 14, 320-327.

BUNDERSON, J. S., \& SUTCLIFFE, K. M. 2002. Comparing alternative conceptualizations of functional diversity in management teams: Process and performance effects. Academy of Management Journal, 45, 875-893.

CARLSON, M., CHARLIN, V., \& MILLER, N. 1988. Positive mood and helping behavior: a test of six hypotheses. Journal of Personality and Social Psychology, 55, 221-229.

CARMELI, A., BRUELLER, D., \& DUTTON, J.E. (2009). Learning behaviours in the workplace: The role of high-quality interpersonal relationships and psychological safety. Systems Research and Behavioral Science, 26, 81-98.

CARMELI, A., \& SCHAUBROECK, J. (2007). The influence of leaders' and other referents' normative expectations on individual involvement in creative work. The Leadership Quarterly, 18, 35-48.

CARMELI, A., \& TISHLER, A. (2004). The relationships between intangible organizational elements and organizational performance. Strategic Management Journal, 25, 1257-1278.

CORTINA, L. M., MAGLEY, V. J., WILLIAMS, J. H., E LANGHOUT, R. D. (2001). Incivility in the workplace: Incidence and impact. Journal of Occupational Health Psychology, 6, 64-80.

DELBECQ, A. \& MILLS, P. K. (1985). Managerial practices that enhance innovation. Organizational Dynamics, $14: 24-34$. DEUTSCH, M. (1958). Trust and suspicion. Journal of Conflict Resolution, 2, 265-279.

DUTTON, J. E. (2003). Energize your workplace. San Francisco: Jossey-Bass.

DUTTON, J. E., \& HEAPHY, E. D. (2003). The power of high-quality connections at work. In K.S. Cameron, J. E. Dutton, \& R. E. Quinn (Eds.), Positive organizational scholarship (pp. 263-278). San Francisco: BerrettKoehler Publishers. 
DUTTON, J. E., ASHFORD, S., O'NEILL, R., \& LAWRENCE, K. (2001). Moves that matter: Issue selling and organizational change. Academy of Management Journal, 4, 716-737.

EDMONDSON, A. C. (1999). Psychological safety and learning behavior in work teams. Administrative Science Quarterly, 44, 350-383.

EDMONDSON, A. C. (2004). Psychological safety, trust, and learning in organizations: A group-level lens. In R. Kramer E K. Cook (Eds.), Trust: Emerging perspectives, enduring questions (pp. 239-272). New York: Russell Sage.

FILIPOWITZ, A. (2006). From positive affect to creativity: The surprising role of surprise. Creativity Research Journal, 18, 141-152.

FINKE, R. A. (1996). Imagery, creativity and emergent structure. Consciousness and Cognition, 5, 381-393.

FOSTER, R. N., \& KAPLAN, S. (2001). Creative destruction: Why companies that are built to last underperform the market - and how to successfully transform them. New York: Currency (Doubleday).

FREDRICKSON, B. (2003). The value of positive emotions. American Scientist, 91, 330-335.

FREDRICKSON, B. (2001). The role of positive emotions in positive psychology: The broaden and build theory of positive emotions. American Psychologist, 56, 218-226.

FRIEDMAN, R.S., \& FORSTER, J. (2002). The influence of approach and avoidance motor actions on creative cognition. Journal of Experimental Social Psychology, 28, 41-55.

GEORGE, J., \& ZHOU, J. (2002). Understanding when bad moods foster creativity and good ones don't: The role of context and clarity of feelings. Journal of Applied Psychology, 87, 687-697.

GILSON, L. L., E SHALLEY, C. E. (2004). A little creativity goes a long way: An examination of teams' engagement in creative processes. Journal of Management, 30, 453-470.

HAIR, J. F. ANDERSON, P. E., TATHAM, R. L., E BLACK, W. C. (1998). Multivariate data analysis. NJ: Prentice Hall.

HARGADON, A. B. (2006). Bridging old worlds and building new ones: Towards a microsociology of creativity. In L. Thompson (Ed.), Creativity and innovation in groups and organizations (pp. 199-216). New York: Erlbaum.

HARGADON, A. B. (1999). Group cognition and creativity in organizations. Research on Managing Groups and Teams, 2, 137-155.

HIRT, E. R., LEVINE, G. M., MCDONALD, H. E., \& MELTON, R. J. (1997). The role of mood in qualitative aspects of performance. Journal of Experimental Social Psychology, 33, 602-629.

HUNTER, S. T., BEDELL, K. E., \& MUMFORD, M. D. (2007). Climate for creativity: A quantitative review. Creativity Research Journal, 19, 69-90.

ISEN, A. M., DAUBMAN, K. A., \& NOWICKI, G. P. (1987). Positive affect facilitates creative problem solving. Journal of Personality and Social Psychology, 47, 1206-1217.

JANSSEN, O. (2004). How fairness perceptions make innovative behavior more or less stressful. Journal of Organizational Behavior, 25, 201-215.

JONES, G. R., \& GEORGE, J. M. (1998). The experience and evolution of trust: Implications for cooperation and teamwork. Academy of Management Review, 23, 531-546.

JORESKOG, K. G., \& SORBOM, D. (1993). LISREL 8: Structural equation modeling with the SIMPLIS command language. Chicago, IL: Scientific International Software.

KAHN, W. A. (1990). Psychological conditions of personal engagement and disengagement at work. Academy of Management Journal, 33, 692-724.

KANFER, R. 1990. Motivation and individual differences in learning: An integration of developmental, differential and cognitive perspectives. Learning and Individual Differences, 2, 221-239.

KANTER, R. B. (1983). The change masters. New York: Simon and Schuster.

KANTER, R. B. (1988). When a thousand flowers bloom: Structural, collective, and social conditions for innovation in organizations. In B. M. Staw E L. L. Cummings (Eds.), Research in organizational behavior (Vol. 10, pp. 169-211). Greenwich, CT: JAI Press.

KARK, R., E CARMELI, A. (2009). Alive and creating: The mediating role of vitality in the relationship between psychological safety and creative work involvement. Journal of Organizational Behavior, Forthcoming.

KAUFMAN, G., \& VOSBURG, S. K. (1997). Paradoxical mode effects on creative problem-solving. Cognition and Emotion, 11, 151-170.

KENNY, D. A., KASHY, D., \& BOLGER, N. (1998). Data analysis in social psychology. In D. Gilbert, S. Fiske, \& G. Lindzey (Eds.), Handbook of social psychology (pp. 233-265). New York: McGraw-Hill.

KLINE, R. B. (1998). Principles and practice of structural equation modeling. New York: The Guilford Press.

KRAMER, R. M. (1999). Trust and distrust in organizations: Emerging perspectives, enduring questions. Annual Review of Psychology, 50, 569-598.

LATHAM, G. P., E PINDER, C. C. 2005. Work motivation theory and research at the dawn of the 21 st Century. Annual Review of Psychology, 56, 485-516.

LEANA, C. R., E BARRY, B. (2000). Stability and change as simultaneous experiences in organizational life. Academy of Management Review, 25, 753-759.

188 
LOSADA, M. (1999). The complex dynamics of high performance teams. Mathematical and Computer Modeling, 30, 179-192.

LOSADA, M., \& HEAPHY, E. (2004). The role of positivity and connectivity in the performance of business teams: A nonlinear dynamics model. American Behavioral Scientist, 47, 740-765.

LOVELACE, K., SHAPIRO, D. L., \& WEINGART, L. R. 2001. Maximizing cross-functional new product teams' innovativeness and constraint adherence. Academy of Management Journal, 44, 779-793.

MACKINNON, D. P., LOCKWOOD, C. M., HOFFMAN, J. M., WEST, S. G., \& SHEETS, V. (2002). A comparison of methods to test mediation and other intervening variables effects. Psychological Methods, 7, 83-104.

MADJAR, N., OLDHAM, G., \& PRATT, M. (2002). There's no place like home? The contributions of work and nonwork sources of creativity support to employees' creative performance. Academy of Management Journal, 4, 757-767.

MARTINDALE, C. (1981). Cognition and consciousness. Homewood, IL: Dorsey.

MAY, D. R., GILSON, R. L., \& HARTER, L. M. (2004). The psychological conditions of meaningfulness, safety and availability and the engagement of the human spirit at work. Journal of Occupational and Organizational Psychology, 77, 11-37.

MAYER, R. C., DAVIS, J. H., \& SCHOORMAN, F. D. (1995). An integrative model of organizational trust. Academy of Management Review, 20, 709-734.

MCCRAE, R. R. (1987). Creativity, divergent thinking, and openness to experience. Journal of Personality and Social Psychology, 52, 1258-1265.

MEDSKER, G. J., WILLIAMS, L. J., \& HOLAHAN, P. J. (1994). A review of current practices for evaluating causal models in organizational behavior and human resources management research. Journal of Management, 20, 439-464.

MILLER, J. B., \& STIVER, I. P. (1997). The healing connection: How women form relationships in therapy and in life. Boston: Beacon Press.

MISHRA, A. K. (1996). Organizational responses to crisis: the centrality of trust. In R. Kramer $\&$ T. Tyler (Eds.), Trust in Organizations (pp. 261-287). Thousand Oaks, CA: Sage.

MITCHELL, T. R., \& DANIELS, D. (2003). Motivation. In W. C. Borman, D. R. Ilgen, \& R. J. Klimoski (Eds.), Handbook of psychology: Industrial and organizational psychology, 12, 225-254. Hoboken, NJ: John Wiley and Sons.

MEDSKER, G. J., WILLIAMS, L. J., \& HOLAHAN, P. J. (1994). A review of current practices for evaluating causal models in organizational behavior and human resources management research. Journal of Management, 20, 439-464.

MUMFORD, M. D., BLAIR, C., DAILEY, L., LERITZ, L. E., \& OSBORN, H. K. (2004). Errors in creative thought: Cognitive biases in a complex processing activity. Journal of Creative Behavior, 40, 75-109.

MUMFORD, M. D., \& GUSTAFSON, S. B. (1988). Creativity syndrome: Integration, application, and innovation. Psychological Bulleting, 103, 27-43.

MUMFORD, M. D., SCOTT, G. M., GADDIS, B., \& STRANGE, J. M. (2002). Leading creative people: Orchestrating expertise and relationships. The Leadership Quarterly, 13, 705-750.

OLDHAM, G. R., \& CUMMINGS, A. (1996). Employee creativity: Personal and contextual factors at work. Academy of Management Journal, 39, 607-634.

PARKER, S. K., WILLIAMS, H., \& TURNER, N. (2006). Modeling the antecedents of proactive behavior at work. Journal of Applied Psychology, 91, 636-652.

PARKER, S. K., \& SPRIGG, C. A. (1999). Minimizing strain and maximizing learning: The role of job demands, job control, and proactive personality. Journal of Applied Psychology, 84, 925-939.

PEARSON, C. M., \& PORATH, C. L. (2005). On the nature, consequences and remedies of workplace incivility: No time for nice? Think again. Academy of Management Executive, 19, 7-18.

PHELAN, S., \& YOUNG, A. M. (2003). Understanding creativity in the workplace: An examination of individual styles and training in relation to creative confidence and creative self-leadership. Journal of Creative Behavior, 37, 266-281.

PODSAKOFF, P. M., MACKENZIE, S. M., LEE, J., E PODSAKOFF, N. P. (2003). Common method variance in behavioral research: A critical review of the literature and recommended remedies. Journal of Applied Psychology, 88, 879-903.

PORATH, C. L., \& EREZ, A. (2007). Does rudeness matter? The effects of rude behavior on task performance and helpfulness. Academy of Management Journal, 50, 1181-1197.

PORATH, C., SPREITZER, G., \& GIBSON, C. (2008). Antecedents and consequences of thriving at work across Six Organizations. A paper presented at the 2008 Academy of Management Meeting in Anaheim, CA.

QUINN, R. W., \& DUTTON, J. E. (2005). Coordination as energy-in-conversation: A process theory of organizing. Academy of Management Review, 30, 38-57.

ROBINSON, S. L. (1996). Trust and breach of the psychological contract. Administrative Science Quarterly, 41, 574-599.

ROUSSEAU, D. M. (1989). Psychological and implied contracts in organizations. Employee Responsibilities and Rights Journal, 2, 121-139. 
ROUSSEAU, D. M., \& PARKS, J. M. (1994). The contracts of individuals and organizations. In L. L. Cummings $\&$ B. M. Staw (Eds.), Research in Organizational Behavior, 15, 1-43. Greenwich, CT: JAI Press.

ROUSSEAU, D. M., SITKIN, S. B., BURT, R. S., \& CAMERER, C. (1998). Not so different after all: A cross-discipline view of trust. Academy of Management Review, 23, 393-404.

SCHUMPETER, J. A. (1975). Capitalism, socialism and democracy. New York: Harper.

SCOTT, S. G., \& BRUCE, R. A. (1994). Determinants of Innovative Behavior: A path model of individual innovation in the workplace. Academy of Management Journal, 37, 580-607.

SHALLEY, C. E., ZHOU, J., \& OLDHAM, G. R. (2004). The effects of personal and contextual characteristics on creativity: Where should we go from here? Journal of Management, 30, 933-958.

SHALLEY, C. E., GILSON, L. L., \& BLUM, T. C. (2000). Matching creativity requirements and the work environment: Effects of satisfaction and intentions to leave. Academy of Management Journal, 43, 215-223.

SHROUT, P. E., \& BOLGER, N. (2002). Mediation in experimental and nonexperimental studies: New procedures and recommendations. Psychological Methods, 7, 422-445.

SONENSHEIN, S., DUTTON, J., GRANT, A., SPREITZER, G., E SUTCLIFFE, K. (2005, August). Narratives of thriving. In Narratives of life in organizations: Bringing organizations to life in and through stories. Symposium conducted at the National Academy of Management Meetings, Hawaii.

SPREITZER, G., SUTCLIFFE, K., DUTTON, J., SONENSHEIN, S., E GRANT, A. M. (2005). A socially embedded model of thriving at work. Organization Science, 16, 537-549.

SPREITZER, G., COBB, A., \& STEVENS, F. (2008). Human thriving: Measurement, validation, and implications for organizations. A paper presented at the 2008 Academy of Management Meeting in Anaheim, CA..

TIERNEY, P., E FARMER, S. M. (2002). Creative self-efficacy: Its potential antecedents and relationship to creative performance. Academy of Management Journal, 45, 1137-1148.

TIERNEY, P., E FARMER, S.M. (2004). The Pygmalion process and employee creativity. Journal of Management, 30, 413-432.

TIERNEY, P., FARMER, S. M., E GRAEN, G. B. (1999). An examination of leadership and employee creativity: The relevance of traits and relations. Personnel Psychology, 52, 591-620.

UNSWORTH, K. (2001). Unpacking creativity. Academy of Management Journal, 26, 289-297.

VINARSKI-PERETZ, H., \& CARMELI, A. (in press). Linking care felt to engagement in innovative behaviors in the workplace: The mediating role of psychological conditions. Psychology of Aesthetics, Creativity, and the Arts.

WARD, T. B. (1994). Structured imagination: The role of category structure in exemplar generation. Cognitive Psychology, 27, 1-40.

WARD, T. B. (2004). Cognition, creativity and entrepreneurship. Journal of Business Venturing, 19, 173-188.

WARD, T. B., PATTERSON, M. J., E SIFONIS, C. M. (2004). The role of specificity and abstraction in creative idea generation. Creativity Research Journal, 16, 1-9.

WARR, P. B. (2007). Work, happiness, and unhappiness. Mahwah, NJ: Lawrence Erlbaum Associates.

WENGER, E. (1998). Communities of practice: learning, meaning and identity. New York: Cambridge University Press.

ZAND, D. E. (1972). Trust and managerial problem solving. Administrative Science Quarterly, 17, $229-239$.

ZHOU, J., E GEORGE, J. (2001). When job dissatisfaction leads to creativity: Encouraging the expression of voice. Academy of Management Journal, 44, 682-696.

Abraham Carmeli, Graduate School of Business Administration, Bar-Ilan University, Ramat Gan 52900, Israel, Email: carmelia@mail.biu.ac.il

Gretchen M. Spreitzer, Stephen M. Ross School of Business, University of Michigan, 701 Tappan St., Ann Arbor, MI 48109-1234, Email: spreitze@umich.edu

\section{ACKNOULEDGEMENTS}

We thank Associate Editor James Kaufman and anonymous reviewers of this journal for their constructive comments and helpful guidance. We also acknowledge Mike Mumford, Sam Hunter and Chris Porath for their thoughtful comments on an earlier version of this manuscript.

Abraham Carmeli is an associate professor of strategy and management at the Graduate School of Business Administration at Bar-Ilan University. He received his Ph.D. from the University of Haifa. His current research interests include top management teams, organizational identification, relational dynamics, crisis management, learning from failures, and creativity at work.

Gretchen M. Spreitzer is a professor of Management and Organizations at the University of Michigan's Ross School of Business. Her research focuses on employee empowerment and leadership development, particularly within a context of organizational change and decline. Her most recent work examines positive deviance and how organizations enable employees to thrive at work.

The authors contributed equally and are listed in alphabetical order. 


\section{APPENDIX 1}

\section{Items used to measure the study variables}

Items measuring employee innovative work behaviors (Alpha $=0.92$ )

I seek out new technologies, processes, techniques, and/or product ideas at work

I generate creative ideas at work

I promote and champion ideas to others at work

I investigate and secure funds needed to implement new ideas

I develop adequate plans and schedules for the implementations of new ideas

I am innovative

\section{Items measuring Thriving (Alpha $=0.94)$}

To what extent do you learn new things at work (learning)

To what extent do the things you learn at work help your in your life (learning)

To what extent do the things you learn at work enable you to thrive in life (learning)

I feel active and energetic at work (vitality)

I have high energy to complete my work (vitality)

During the working day I feel I am full of energy (vitality)

I have the energy to successfully do my job (vitality)

When I come to work in the morning I have energy for the new day (vitality)

I feel a lot of excitement when I am doing my work (vitality)

The work in this organization gives me positive energy (vitality)

When I am at work I feel vital and alive (vitality)

Items measuring connectivity (Alpha $=0.93)$

We have very open relationships

We are always open to listening to our coworkers' new ideas

We are very open to diverse influences, even if they come from unconventional sources, such as new employees, customers, etc.

We are attentive to new opportunities that can make our system more efficient and effective

The relationships we have enable us to generate new things

The relationships we have enable us to learn new things

The relationships we have encourage us to seek out new opportunities

Items measuring trust (Alpha $=0.87$ )

I believe my employer has high integrity

I can expect my employer to treat me in a consistent and predictable fashion

In general, I believe my employer's motives and intentions are good

My employer is open and up front with me 